\title{
Isosexual precocity: uncommon presentation of a common disorder
}

\author{
A Bhansali, A Kashyap, S Lodha, N Kotwal, B Ganapathi, B R Mittal, R J Dash
}

A 7-year-old girl presented with bilateral symmetrical enlargement of breasts of one year duration and one episode of vaginal bleed in August 1996. She did not have history of seizure disorder, meningitic or encephalitic illness, head injury or administration of oestrogen-containing preparations. She was an active child and had good scholastic performance.

On examination, her height was $108 \mathrm{~cm}$ (<3rd centile), weight $21 \mathrm{~kg}(10-25$ th centile) and bone age was 3 years. Her pubertal status (Tanner) was $\mathrm{B}_{3} \mathrm{~A}_{1} \mathrm{P}_{1}$ (figure 1 ). She had no goitre and her deep tendon reflexes showed delayed relaxation.

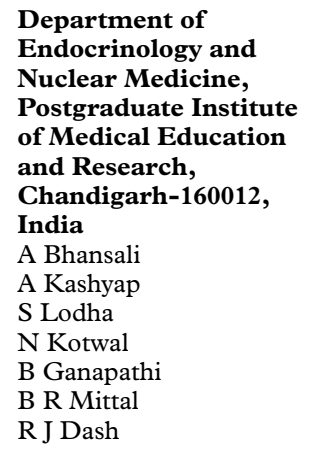

Submitted 29 April 1999 Accepted 14 May 1999

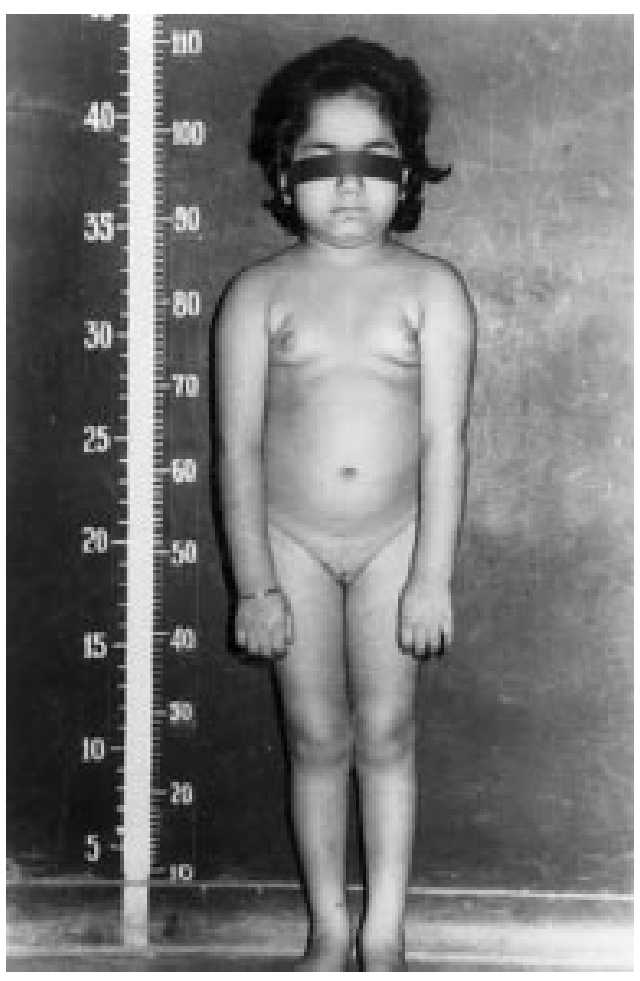

Figure 1 Photograph showing short child with premature breast enlargement (reproduced with the parents' permission)

\section{Questions}

1 What is the diagnosis?

2 What investigations would you perform next?

3 How would you treat this case? 
Answers

QUESTION 1

The diagnosis is juvenile hypothyroidism presenting with isosexual precocious puberty.

QUESTION 2

Serum thyroxine $\left(\mathrm{T}_{4}\right)$, thyroid-stimulating hormone (TSH), prolactin and thyroid scan are required to establish the diagnosis. Her serum $\mathrm{T}_{4}$ was $10 \mathrm{ng} / \mathrm{ml}$ (normal $60-120 \mathrm{ng} / \mathrm{ml}$ ), $\mathrm{TSH}$ $50 \mu \mathrm{U} / \mathrm{ml}(0.5-5 \mu \mathrm{U} / \mathrm{ml})$, prolactin $20 \mathrm{ng} / \mathrm{ml}$ $(6-25 \mathrm{ng} / \mathrm{ml})$ and ${ }^{99 \mathrm{~m}} \mathrm{Tc}$ thyroid scan revealed a lingual thyroid (figure 2). As a lingual thyroid is smaller in mass, it fails to compensate for the increasing need of a growing child and results in hypothyroidism.

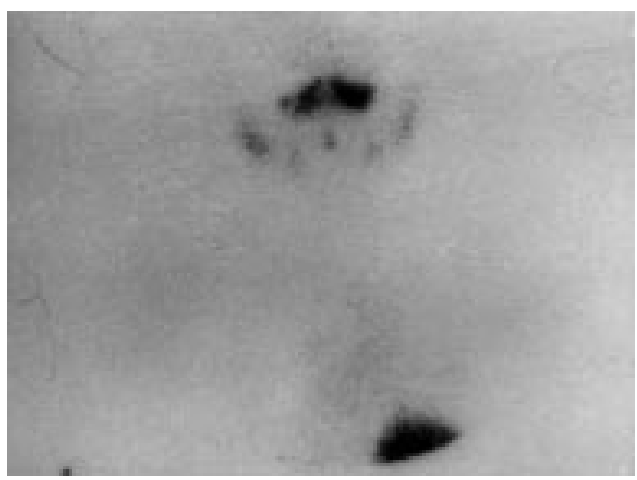

Figure $2{ }^{99_{\mathrm{m}}} \mathrm{Tc}$ thyroid scan showing tracer uptake in lingual region only

QUESTION 3

After confirmation of diagnosis she was put on thyroxine replacement therapy in gradually increasing doses $(25-100 \mu \mathrm{g})$. She had 'catch up' growth, regression of breasts and no recurrence of menses in 18 months of follow-up with normalisation of serum TSH $(0.25 \mu \mathrm{U} / \mathrm{ml})$.

\section{Discussion}

Isosexual precocity is a rare monosymptomatic manifestation of juvenile hypothyroidism and other presenting features are summarised in box 1. ${ }^{1}$ This was first described by Van Wyk-Grumbach in a series of three cases who presented with premature thelarche, galactorrhoea and menarche. ${ }^{2}$ In this disorder the pubertal events are associated with decelerated growth and retarded bone age. The exact cause of precocity in hypothyroidism is not clear.

1 Mahoney CP. Evaluating the child with short stature. Pediat Clin North Am 1987;34:825-49.

2 Van Wyk JJ, Grumbach MM. Syndrome of precocious menstruation and galactorrhoea in juvenile hypothyroidism: an example of hormonal overlap in pituitary feed back. F Pediatr 1960;57:416-35

3 Suter SN, Kaplan SL, Aubert ML. Plasma prolactin and Suter SN, Kaplan SL, Aubert ML. Plasma prolactin and
thyrotropin and the response to thyrotropin releasing factor thyrotropin and the response to thyrotropin releasing factor
in children with primary and tertiary hypothyroidism. $f$ Clin Endocrinol Metab 1978;47:1015-20.
Monosymptomatic presentations of juvenile hypothyroidism

- short stature

- delayed puberty

- poor scholastic performance

- puberty menorrhagia

- isosexual precocity (Van Wyk-Grumbach syndrome)

Box 1

\section{Learning points}

- isosexual precocity is a monosymptomatic but rare presentation of juvenile hypothyroidism

- isosexual precocity with short stature and retarded bone age is a strong pointer towards diagnosis of thyroprivic hypothyroidism

- thyroxine therapy leads to complete arrest and regression of disorder

Box 2

Postulated mechanisms are 'specificity spillover' which means positive feed-back effect of low serum thyroxine on pituitary gonadotropins as they are also glycoprotein hormones like TSH. $^{2}$ Hyperprolactinaemia, ${ }^{3}$ reduced gonadotropin clearance and decreased dopaminergic and opioid tone at the hypothalamo-pituitary axis ${ }^{4}$ are other plausible explanations. Elevated serum gonadotropins and oestradiol levels sometimes confuse the picture with gonadotropin-dependent precocious puberty (GDPP). However, this can be differentiated by the gonadotropin response to leutinising hormone releasing hormone (LHRH) which is present in GDPP but not in hypothyroidism-associated precocity. ${ }^{5}$ Our patient had normal prolactin $(20 \mathrm{ng} / \mathrm{ml})$ and elevated gonadotropins (leutinising hormone $6.5 \mathrm{IU} / 1$, follicle-stimulating hormone 12.5 IU/l) and oestradiol (163 pmol/l) levels, however, her gonadotropin response to LHRH was prepubertal.

Thyroxine replacement therapy in optimal doses results in 'catch up' growth and complete arrest and regression of pubertal events. ${ }^{6}$

\section{Final diagnosis}

Juvenile thyroprivic hypothyroidism presenting as isosexual precocious puberty (Van WykGrumbach syndrome).

Keywords: precocious puberty; juvenile hypothyroidism; lingual thyroid

4 Thomas R, Reid RL. Thyroid disease and reproductive dysfunction. A review. Obstet Gynecol 1987;70:789-98

5 Castro-Magana M, Angulo M, Canas A, Sharp A, Fuentes B. Hypothalamo pituitary gonadal axis in boys with primary hypothyroidism and macro-orchidism. F Pediatr 1988;112: 397-402.

6 Stein DT. South western internal medicine conference: New development in the diagnosis and treatment of sexual precocity. Am f Med Sci 1992;303:53-71. 